\title{
Umha quantificaçom da dependência agroalimentar exterior da Galiza a partir das tabelas input-output 1998 e 2005i
}

Recibido: 27 xullo 2012 / Aceptado: 29 outubro 2012

(C) IBADER- Universidade de Santiago de Compostela 2012
Rascunho $\mathrm{O}$ objectivo deste trabalho é realizar unha primeira achega á quantificaçom da dependencia agroalimentar galega do exterior utilizando como fonte os dados das tabelas input-output de 1998 e 2005. As tabelas input-output som um instrumento privilegiado para analisar a dependência alimentar do exterior dumha economia subestatal como a galega porque informam do conjunto do comércio exterior non só de fóra do Estado Espanhol senom que tamém oferecem dados dos intercambios com outras áreas do Estado. É um facto conhecido o peso que tem a actividade agraria na economía galega, especialmente em termos de emprego. A pesar desta relevancia quantitativa, o nosso país apresenta umha balança exterior agroalimentária fortemente deficitária. Em 2005 Galiza apresentava um acusado défice e a taxa de cobertura (exportaçons/importaçons) situava-se arredor de dous terços. Este défice deve-se basicamente aos produtos vegetais, tanto elaborados como sem elaborar. A pesar da especializaçom gandeira tambén apresentam um saldo negativo produtos transformados de preparados cárnicos e inclusive os derivado lácteos pondo de manifesto o escasso desenvolvimento do sector agroindustrial galego. Os resultados ofrecidos permitem pôr em causa as orientaçons da política agroalimentaria que acentuárom a dependência exterior e mesmo ponhem em risco o modelo gandeiro no que se asentou a especializaçom da agricultura galega.

Bernardo Valdês Paços · Mar Pérez Fra · Ana I. García Arias Escola Politécnica Superior

Área de Economía Socioloxía e Política Agraria

Avda Benigno Ledo s/n

27002 Lugo

Ana I. García

Tel: 982-823226

E-mail: anaisabel.garcia@usc.es
Palavras chave Cadeia agro-alimentar, segurança agroalimentar, metodologia input-output, Galiza, Comercio Exterior.

Abstract This paper aims to quantify the dependence from abroad of the Galician agri-food system using data from input-output tables 1998-2005. The input-output tables are a sound instrument for analyzing food dependence of a regional economy as Galicia since they offer information for the whole foreign trade including regions inside the Spanish State. Despite the quantitative relevance of agriculture in Galician economy -especially in terms of employment- the Commercial Balance for food products presents a deep deficit. In 2005 the coverage rate (exports/imports) stood surroundings of two-thirds. This deficit is largely due to vegetable products, both for human consumption and for animal consumption, and products made of vegetable origin.In spite of their cattle specialization Galicia also have a negative balance of processed products including prepared meat and milk derived. This fact underlines the scarce development of the agro-industrial sector in Galicia. The results of input-output tables about the agri-food deficit evolution put into question the followed orientations of our agricultural policy. This policy doesn't counteract the external dependency and put into risk the specialization model of Galician agriculture.

Key words Agri-food chain, food sovereignity, input-output methodology, Galician Economy, External Trade.

\section{Introduçom}

O conceito de segurança alimentar foi evoluindo ao longo do tempo. A Declaraçom Universal dos Direitos Humanos aprovada polas Naçons Unidas (1948) no seu art. 25.1 proclama que "toda pessoa tem direito a um padrom de vida capaz de assegurar a si e a sua família saúde e bem-estar, inclusive alimentaçom,...". No ano 1996 a FAO na Declaraçom de Roma sobre segurança alimentar define a 
existência de segurança alimentar quando todas as pessoas têm acesso em todo momento a umha quantidade suficiente de alimentos inócuos e nutritivos para ter umha vida activa e saudável (Golay 2009). Polo tanto, e em qualquer caso a segurança alimentar é um conceito que inclui quatro dimensons principais: disponibilidade, acesso, utilizaçom e estabilidade.

Nas últimas décadas, ao tempo que avançava a mundializaçom, desde os Estados centrais e também desde organismos internacionais como o Banco Mundial ou o GATT/OMC primou-se umha abordagem centrada nos mecanismos de mercado como principal ferramenta para garantir a segurança alimentar, incluindo o abastecimento nos mercados internacionais.

A experiência recente sem embargo evidencia os perigos de manter umha forte dependência dos mercados internacionais para o abastecimento agroalimentar. Afectando à estabilidade na subministraçom e dificultando/impossibilitando o acesso polo encarecimento. As duas bolhas nas quotizaçons internacionais das principais commodities agroalimentares (finais de 2007começos de 2008 e finais de 2010) supugérom umha ameaça á segurança alimentar (Gráfico 1), especialmente grave para os países com menores níveis de rendimento per capita e fortemente dependentes das importaçons para a sua alimentaçom, dando lugar a um forte incremento na factura destas importaçons ao tempo que descende a quantidade física importada. A própria $\mathrm{FAO}$, referindo-se à bolha de 2006-2008, reconhece que "los países más expuestos a las fluctuaciones de los precios en los mercados internacionales eran en general los países pobres importadores de alimentos: disponían de escasas reservas y recursos presupuestarios insuficientes para adquirir alimentos a precios altos; tampoco tenían la opción de imponer restricciones a las exportaciones. Estos países fueron los principales perjudicados por la crisis ya que los precios internos de los alimentos básicos aumentaron considerablemente en sus mercados". (FAO, 2011)

Este encarecimento dá lugar à sua vez a que a populaçom procure alternativas alimentares mais baratas embora em muitos casos sejam dumha pior qualidade nutritiva (Graziano da Silva, J. e Tavarez, L., 2008)
Dito isto, é preciso apontar que a declaraçom do Foro Mundial da Soberania Alimentar da Havana de 2001 explicita também que a soberania alimentar nom pode ser entendida como autarquia, autosuficiência plena ou a desapariçom do comércio agroalimentar. A soberania alimentar é um conceito político, nom contável, e em termos políticos cabe entendê-lo como o direito dos povos a definir as suas próprias políticas e estratégias sustentáveis de produçom, distribuiçom e consumo de alimentos. Embora nom seja correto abordar a soberania alimentar a partir dumha aproximaçom unicamente quantitativa, utilizando os fluxos do comércio exterior, tampouco o seria pensar na soberania alimentar fazendo abstracçom da maior ou menor dependência do mercado exterior para o abastecimento alimentar.

Nesta perspetiva situa-se o presente trabalho, o seu objetivo é avaliar a dependência agroalimentar galega do exterior. Medindo esta dependência nom em termos de componentes nutritivos, mas em termos de valor. Ao longo das últimas três décadas a economia galega e em particular o sector agroalimentar experimentárom umha crescente apertura comercial internacional fruto dos câmbios no marco institucional: a integraçom na Comunidade Européia (posteriormente Uniom Européia), as reformas da PAC ou o acordo final na Rolda Uruguai do GATT. Evidentemente a situaçom da Galiza nom é dos países aos que a FAO se referia na cita anterior. Contudo, e como veremos posteriormente, a dependência do exterior fixo que as altas de preços também tivessem notáveis repercusons na agricultura galega. Este feito assim como a própria evoluçom do déficit agroalimentar ponhem em causa as orientaçons da política agroalimentar seguidas na Galiza que acentuárom a dependência exterior com os conseguintes riscos.

\section{Material e métodos}

Para quantificar os fluxos agroalimentares com o exterior utilizamos as tabelas input-output, em concreto o Marco Input-Output da Galiza 2005 elaborado polo IGE (no sucessivo MIOGA-2005), comparando estes dados com os de 1998. Porém os câmbios metodológicos obrigam a

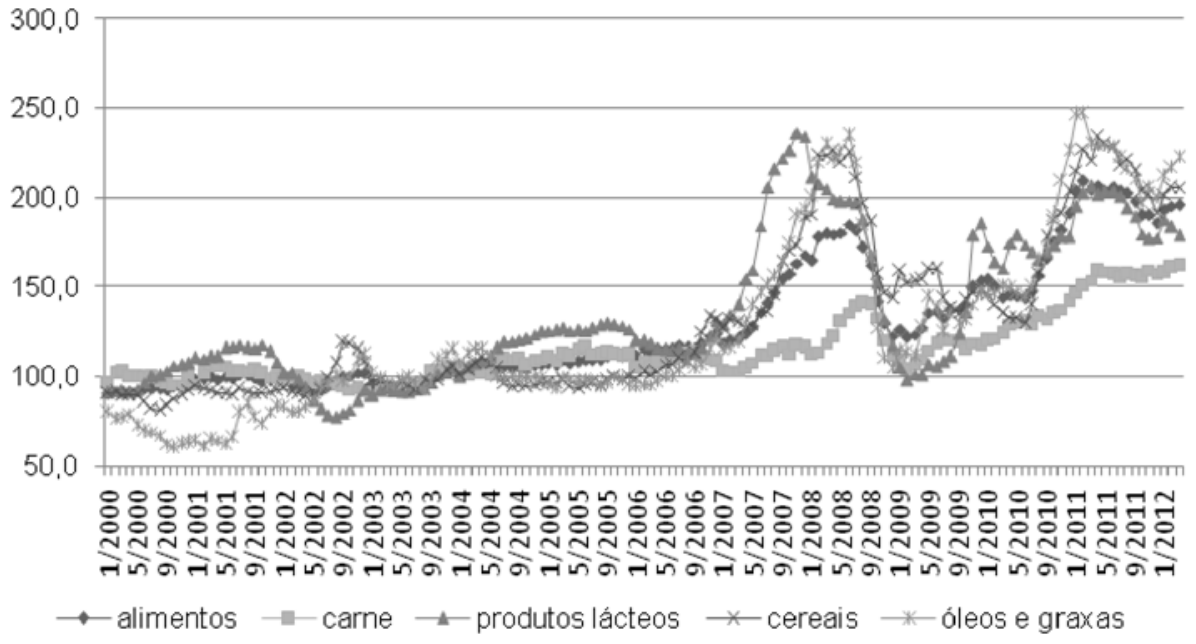

Gráfico 1.- Índizes da FAO sobre preços dos alimentos Evoluçom em termos reais; índizes base 20022004=100. Fonte: elaboraçom própia a partir dos dados da FAO 
realizar com precauçom esta comparaçom, fixando-nos nom tanto na variaçom exacta das magnitudes mas nas tendências.

O Sistema Europeio de Contas oferece normas contábeis homogêneas e sustenta o emprego do método Input-Output (I-O), un sistema de tabelas relacionadas que tratan de representar o fluxo econômico entre os distintos sectores produtivos. As unidades de produçom agrúpanse en ramas homogeneizadas e recolhesse o fluxo entre elas, assim como a distribuçom do valor acrescentando entre os fatores de produçom.

A metodologia input-output desenvolvida por Leontief nos anos 40 (Leontief,1986) representa unha valiosa ferramenta para a análise dos sistemas produtivos xá que supõe a aplicaçom do conceito de sistema á economia. O economista tem a possibilidade de discernir os efeitos duma atividade produtiva sobre o resto podendo desagregar os efeitos por sectores e agentes econômicos. A informaçom organízase em forma de matriz onde se representan as interrelaçoms entre os diferentes sectores incluindo os fogares e a produçom vendida ao exterior.

As tabelas input-output som um instrumento privilegiado para analisar a dependência alimentar do exterior dumha economia subestatal (Llano Verduras, 2004) como a galega porque, a diferença doutras fontes estatísticas referidas ao comércio exterior, nom informa unicamente dos intercâmbios com o exterior do Estado Espanhol senom que também oferece dados dos intercâmbios com outras áreas do Estado. Ademais no caso concreto dos fluxos com o exterior do Estado estes dados contrastárom-se com os do Departamento de Alfândegas da Agência Tributaria.

\section{Resultados e discusión}

É um facto amplamente conhecido que o processo de crescimento económico dá lugar a umha perda de peso do sector agrário no conjunto da economia. A isto contribue a crescente integraçom mercantil do sector agrário. Precisamente os alimentos adquiridos polos consumidores som, cada vez em maior medida, gerados pola indústria. Esta perda de peso da agricultura frente às actividades de transformaçom industrial fixo que a Economia Agrária dirigisse a súa atençom cara ao conjunto de atividades relacionadas com a agro-industria. Destarte L. Malassis (1979) formula o conceito de sistema agro-alimentar e define-o como o conjunto de actividades económicas que servem para satisfazer as necessidades alimentares da populaçom.

Galiza nom foi alheia a esta evoluçom. Segundo a MIOGA2005 o gasto em consumo final em produtos agrícolas ou gadeiros ascendeu a 893 milhons de euros a preços de adquisiçom enquanto as despesas em consumo final em transformados ascendérom a perto de 4.000 milhons de euros. Tendo em conta isto a nossa análise nom pode referir-se unicamente aos produtos agrários sem transformar senom que deve incluir o conjunto de produtos agroalimentares, procedentes da agricultura ou da indústria alimentar.

\section{O comércio externo agroalimentar da Galiza}

\section{a) As importaçons}

Segundo o MIOGA-2005 as importaçons de produtos agroalimentares representam quase unha terça parte $(32,5 \%)$ da oferta interior destes produtos (tabela 1). As importaçons suponhem mais de $50 \%$ do abastecimento interior nos produtos transformados para consumo humano derivados de matérias-primas vegetais (vinho; frutas e hortaliças preparadas e em conserva; graxas e óleos vegetais; produtos do moinho, amidos e amiláceos), mas também nos produtos cárneos, superam $40 \%$ nos produtos vegetais sem transformar e inclusive nos derivados lácteos se aproximam a esse $40 \%$. Unicamente em quatro categorias de produtos as importaçons nom alcançam $30 \%$ da oferta inferior: produtos gadeiros, carne fresca, refrigerada ou congelada, leite de consumo e alimentos preparados para animais.

\begin{tabular}{|c|c|c|c|c|}
\hline \multirow[b]{3}{*}{ Produtos agrícolas } & \multirow{2}{*}{\multicolumn{2}{|c|}{$\begin{array}{l}2005 \\
\text { Importaçons Exportaçons/ } \\
\text { /oferta (\%)empregos (\%) }\end{array}$}} & \multirow{2}{*}{\multicolumn{2}{|c|}{$\begin{array}{c}1998 \\
\text { Importaçons Exportaçons/ } \\
\text { /oferta }(\%) \text { empregos }(\%)\end{array}$}} \\
\hline & & & & \\
\hline & $42,8 \%$ & $7,2 \%$ & $50,0 \%$ & $17,6 \%$ \\
\hline Produtos gadeiros & $4,7 \%$ & $33,7 \%$ & $1,0 \%$ & $26,4 \%$ \\
\hline Carne fresca, refrigerada ou congelada & $11,2 \%$ & $20,9 \%$ & $33,1 \%$ & $29,3 \%$ \\
\hline Produtos cárneos & $65,5 \%$ & $7,4 \%$ & $58,5 \%$ & $26,3 \%$ \\
\hline Leite de consumo & $9,5 \%$ & $53,8 \%$ & $5,1 \%$ & $62,2 \%$ \\
\hline Derivados lácteos e geados & $36,9 \%$ & $33,8 \%$ & $22,2 \%$ & $60,7 \%$ \\
\hline Alimentos preparados para animais & $6,0 \%$ & $14,8 \%$ & $7,8 \%$ & $33,8 \%$ \\
\hline Vinho (em 1998 vinho e bebidas alcoólicas) & $56,4 \%$ & $12,4 \%$ & $62,1 \%$ & $17,2 \%$ \\
\hline Outras bebidas alcoólicas & $37,3 \%$ & $24,3 \%$ & & \\
\hline Águas minerais e bebidas sem álcool & $38,7 \%$ & $8,2 \%$ & $27,0 \%$ & $18,0 \%$ \\
\hline Frutas e hortaliças, prep. e em conserva & $61,5 \%$ & $7,0 \%$ & $46,5 \%$ & $32,4 \%$ \\
\hline Graxas e óleos vegetais ou animais & $63,2 \%$ & $15,3 \%$ & $57,5 \%$ & $51,9 \%$ \\
\hline Prod. do moinho, amidons e amiláceos & $75,3 \%$ & $7,0 \%$ & $90,6 \%$ & $35,3 \%$ \\
\hline Outros produtos alimentares & $56,8 \%$ & $6,3 \%$ & $45,5 \%$ & $24,8 \%$ \\
\hline Tabaco manufacturado & $100,0 \%$ & & $55,7 \%$ & $43,6 \%$ \\
\hline Total Complexo de Produçom Agro & $32,5 \%$ & $18,7 \%$ & $30,0 \%$ & $32,8 \%$ \\
\hline
\end{tabular}

Tabela 1.- Índizes importaçons/oferta e exportaçons/empregos. Galiza 1998 e 2005. Fonte: elaboraçom própia a partir de IGE, Marco Input-Output de Galicia 1998 e 2005 
É habitual que numha economia de âmbito inferior ao estatal as importaçons representem umha parte importante da oferta interior. Agora bem, é necessário salientar que em comparaçom com 1998 observa-se um incremento no peso das importaçons na oferta interna, de $30 \%$ a $32,5 \%$. Ademais este incremento continua a tendência observada na década de noventa. Segundo as tabelas input-output de 1990 as importaçons representavam $24,5 \%$ da oferta interior (Valdês. B. e López, E., 2008) nessa data, embora as comparaçons devam ser tomadas com precauçom polos câmbios metodológicos.

\section{b) As exportaçons}

As exportaçons suponhem $18,7 \%$ dos empregos dos produtos agroalimentários em 2005 (tabela 1). O peso das exportaçons é maior nos produtos de origem gadeira (tanto elaborados como sem elaborar) como corresponde à especializaçom gadeira da agricultura galega. Destacam o leite de consumo $(53,8 \%)$, os derivados lácteos $(33,8 \%)$ e os produtos gadeiros $(33,7 \%)$.

Comparando estas cifras com as de 1998 destaca a forte reduçom da importância relativa das exportaçons, (de $32,8 \%$ dos empregos em 1998 ao 18,7\% em 2005), invertendo assim a evoluçom constatada no período 19901998

\section{c) A balança exterior agroalimentar}

Entre 1998 e 2005, o mercado externo (tanto do resto do Estado como do estrangeiro) perdeu importância como saída para os produtos agroalimentares galegos; enquanto os bens importados (do resto do Estado e/ou do estrangeiro) fórom ganhando quota de mercado na Galiza (tabela 2). O que implicou em termos líquidos umha importante diminuiçom do nível de auto-abastecimento.

Como consequência disso, em 2005 o comércio agroalimentar de Galiza apresentava um déficit de 895 milhons de euros. A taxa de cobertura era de $68,4 \%$, isto é, as exportaçons cobrírom pouco mais de $2 / 3$ das importaçons. A maior parte do nosso comercio agroalimentar (mais de $80 \%$ das exportaçons e importaçons) tivo lugar com o resto do Estado, sendo aqui onde se concentrou mais de $80 \%$ do déficit global. Porém a interpretaçom deste dado deve ser feita com precauçom porque nesta partida podem-se incluir produtos procedentes de fora do Estado, mas importados por empresas com sede fora da Galiza.

Os intercâmbios fora do EE também apresentavam um saldo negativo, pequeno com o resto da UE e muito mais importante com o resto do mundo onde as exportaçons só cobriam 1/5 das importaçons (tabela 2).

Por produtos o déficit centrava-se nos produtos agrícolas sem transformar, tanto os destinados ao consumo humano como os utilizados para a elaboraçom de raçons para o gado, e nos produtos elaborados de origem vegetal. Unicamente existia um superávit nos produtos gadeiros sem transformar, no leite de consumo, na carne fresca, refrigerada ou congelada e nos alimentos para animais.
É obrigado assinalar um facto especialmente chamativo, dentro dos derivados gadeiros destaca o menor peso relativo das exportaçons e a maior importância das importaçons nos produtos cárneos e derivados lácteos em comparaçom, respectivamente, com a carne fresca, refrigerada ou congelada e com o leite de consumo. O resultado é que enquanto Galiza registra um saldo comercial exterior positivo no leite embalado e na carne fresca, apresenta um saldo ligeiramente negativo nos derivados lácteos e fortemente negativo nos produtos cárneos. Estes dados evidenciam a extrema debilidade da indústria alimentar radicada na Galiza nos derivados que geram um maior valor acrescentado e que também som em boa medida os que contam com umha procura mais dinâmica.

\section{d) A evoluçom entre 1998 e 2005}

A comparaçom com os dados de 1998 mostra que nesse período se acelerou o crescimento do déficit exterior agroalimentar que já se observava entre 1990 e 1998 (Valdês, B. e López, E., 2008). O saldo negativo da balança agroalimentar em 2005 multiplicava por 4,5 o que havia em 1998, e neste período a taxa de cobertura diminuiu 20 pontos: de $88,9 \%$ a $68,4 \%$. Em termos absolutos fórom os intercâmbios com o resto do Estado os que experimentárom um maior incremento do déficit, que passou de 215 milhons de euros em 1998 a 730 em 2005, baixando a taxa de cobertura do $85,5 \%$ ao $68,8 \%$. Sem embargo em termos relativos o deterioro mais acusado deu-se no comércio com o resto da UE, que passou dum forte superávit em 1998 a um saldo ligeiramente negativo em 2005. Com o resto do mundo a situaçom permaneceu mais estável, mantendo em todo caso umha taxa de cobertura muito baixa, 20,2\% em 2005. À hora de interpretar estes dados devemos ter em conta que o $1^{\circ}$ de maio de 2004 a UE se ampliou com a adesom de dez novos Estados, polo que os dados de 1998 e 2005 nom som perfeitamente comparáveis quando falamos do resto da UE ou do resto do mundo.

Por produtos, entre os que tinham um saldo positivo em 1998 unicamente aumentou o superávit comercial no período 1998-2005 dos produtos gadeiros sem elaborar e do leite de consumo; sendo de salientar também a evoluçom positiva na carne fresca, refrigerada ou congelada, que passou dum déficit a um importante superávit. No sentido contrário, experimentárom um notável deterioro da balança comercial os produtos cárneos e os derivados lácteos, isto é os produtos de maior valor acrescentado; o que no primeiro caso se traduziu numha forte ampliaçom do déficit existente em 1998, enquanto que no segundo levou a passar dum claro superávit a um pequeno saldo negativo. De todos modos, a forte ampliaçom do déficit global da balança agroalimentar deveu-se principalmente aos produtos transformados de origem vegetal (frutas e hortaliças preparadas e em conserva, graxas e aceites, outros produtos alimentares e tabaco), junto às aguas minerais e outras bebidas sem álcool. Neste âmbito só se constata unha evoluçom positiva, com umha reduçom do déficit inicial, no vinho. 
Dado o intenso deterioro da balança agroalimentar que mostram esses dados, consideramos conveniente contrastá-los com outras fontes estatísticas. Nom obstante, esta é umha difícil tarefa. De facto é impossível para o comércio com outras Comunidades Autónomasii, onde se concentrou a maior parte da ampliaçom do déficit. Para os intercâmbios com o exterior do Estado si contamos com dados anuais, procedentes do Departamento de Alfândegas da Agência Tributária.

As cifras confirmam que o saldo da balança agroalimentar da Galiza com o exterior do Estado se deteriorou no período 1998-2005, passando dum ligeiro superávit a um claro déficitiii.

\begin{tabular}{|c|c|c|c|c|}
\hline \multicolumn{5}{|c|}{ A. Saldo (exportaçons-importaçons) (miles euros) } \\
\hline & $\begin{array}{c}\text { Resto do } \\
\text { Estado }\end{array}$ & $\begin{array}{l}\text { Resto da } \\
\text { U.E. }\end{array}$ & $\begin{array}{l}\text { Resto do } \\
\text { Mundo }\end{array}$ & Total \\
\hline Produtos agrícolas & -206.265 & -50.497 & -86.657 & -343.419 \\
\hline Produtos gadeiros & 416.848 & 16.661 & 631 & 434.140 \\
\hline $\begin{array}{l}\text { Carne fresca, refrigerada ou } \\
\text { congelada }\end{array}$ & 61.309 & 60.008 & 35 & 121.352 \\
\hline Produtos cárneos & -215.948 & 5.852 & 320 & -209.776 \\
\hline Leite de consumo & 354.277 & 537 & 10 & 354.824 \\
\hline Derivados lácteos e geados & -6.424 & -9.646 & 4.353 & -11.717 \\
\hline Alimentos preparados para animais & 69.978 & 7.039 & -18.439 & 58.578 \\
\hline $\begin{array}{l}\text { Vinho (em } 1998 \text { vinho e bebidas } \\
\text { alcoólicas) }\end{array}$ & -142.919 & 3.717 & 15.450 & -123.752 \\
\hline Outras bebidas alcoólicas & -33.991 & 8.616 & -3.023 & -28.398 \\
\hline $\begin{array}{l}\text { Águas minerais e bebidas sem } \\
\text { álcool }\end{array}$ & -126.711 & 1.732 & 488 & -124.491 \\
\hline $\begin{array}{l}\text { Frutas e hortaliças, prep. e em } \\
\text { conserva }\end{array}$ & -58.406 & 915 & -6.087 & -63.578 \\
\hline Graxas e óleos vegetais ou animais & -188.524 & 5.804 & -44.294 & -227.014 \\
\hline $\begin{array}{l}\text { Prod. do moinho, amidons e } \\
\text { amiláceos }\end{array}$ & -97.390 & -4.654 & -140 & -102.184 \\
\hline Outros produtos alimentares & -505.399 & 9.268 & -2.750 & -498.881 \\
\hline Tabaco manufacturado & -50.490 & -77.403 & -3.483 & -131.376 \\
\hline $\begin{array}{l}\text { Total Complexo de Produçom } \\
\text { Agroalimentar }\end{array}$ & -730.055 & -22.051 & -143.586 & -895.692 \\
\hline \multicolumn{5}{|c|}{ B. Taxa de cobertura (exportaçons/importaçons)(\%) } \\
\hline & $\begin{array}{l}\text { Resto do } \\
\text { Estado }\end{array}$ & $\begin{array}{l}\text { Resto da } \\
\text { U.E. }\end{array}$ & $\begin{array}{l}\text { Resto do } \\
\text { Mundo }\end{array}$ & Total \\
\hline Produtos agrícolas & $29,6 \%$ & $36,6 \%$ & $0,1 \%$ & $25,3 \%$ \\
\hline Produtos gadeiros & $1577,1 \%$ & $141,2 \%$ & $517,9 \%$ & $730,5 \%$ \\
\hline $\begin{array}{l}\text { Carne fresca, refrigerada ou } \\
\text { congelada }\end{array}$ & $165,6 \%$ & $613,5 \%$ & $101,9 \%$ & $213,5 \%$ \\
\hline Produtos cárneos & $10,8 \%$ & $685,2 \%$ & & $13,7 \%$ \\
\hline Leite de consumo & $584,5 \%$ & $475,5 \%$ & & $584,3 \%$ \\
\hline Derivados lácteos e geados & $95,2 \%$ & $73,6 \%$ & & $93,2 \%$ \\
\hline Alimentos preparados para animais & $575,5 \%$ & $255,6 \%$ & $0,5 \%$ & $255,1 \%$ \\
\hline $\begin{array}{l}\text { Vinho (em } 1998 \text { vinho e bebidas } \\
\text { alcoólicas) }\end{array}$ & $15,3 \%$ & $1024,6 \%$ & $43016,7 \%$ & $26,8 \%$ \\
\hline Outras bebidas alcoólicas & $72,5 \%$ & $205,0 \%$ & $14,5 \%$ & $79,0 \%$ \\
\hline $\begin{array}{l}\text { Águas minerais e bebidas sem } \\
\text { álcool }\end{array}$ & $21,4 \%$ & $155,4 \%$ & & $24,3 \%$ \\
\hline $\begin{array}{l}\text { Frutas e hortaliças, prep. e em } \\
\text { conserva }\end{array}$ & $4,9 \%$ & $117,9 \%$ & $10,7 \%$ & $13,3 \%$ \\
\hline Graxas e óleos vegetais ou animais & $24,0 \%$ & $153,1 \%$ & $8,3 \%$ & $26,1 \%$ \\
\hline $\begin{array}{l}\text { Prod. do moinho, amidons e } \\
\text { amiláceos }\end{array}$ & $8,6 \%$ & $32,7 \%$ & $39,7 \%$ & $10,1 \%$ \\
\hline Outros produtos alimentares & $6,8 \%$ & $140,7 \%$ & $72,9 \%$ & $13,3 \%$ \\
\hline Tabaco manufacturado & $0,0 \%$ & $0,0 \%$ & $0,0 \%$ & $0,0 \%$ \\
\hline $\begin{array}{l}\text { Total Complexo de Produçom } \\
\text { Agroalimentar }\end{array}$ & $68,8 \%$ & $92,9 \%$ & $20,2 \%$ & $68,4 \%$ \\
\hline
\end{tabular}

Tabela 2.- Saldo e taxa de cobertura do comércio exterior de produtos agroalimentares. Galiza 2005. Fonte: elaboraçom própia a partir de IGE, Marco Input-Output de Galicia 2005

ii: Sobre estes fluxos inter-regionais unicamente contamos com as estimaçons recolhidas na base de dados C-intereg, mas o nível de desagregaçom da informaçom nom permite examinar o que nos interessa, o comércio de bens agroalimentares.

iii: Nom obstante, a evoluçom negativa é de muita menor magnitude que a oferecida polo MIOGA-2005, de tal modo que o déficit estimado para 2005 limitava-se a 22 millhons de euros. 
Finalmente, observa-se que o deterioro registrado entre 1998 e 2005 nom tivo continuidade nos seguintes anos. No último lustro da primeira década deste século o facto que destaca é a instabilidade, com anos nos que o saldo passou a ser novamente positivo e outros nos que foi claramente negativo.

\section{Factores explicativos}

Os dados antes expostos ponhem de manifesto a acusada dependência exterior de Galiza para garantir o seu abastecimento alimentar. Feito que é certamente assinalável numha economia como a galega, na qual a agricultura tem um peso em termos de produçom e de emprego muito superior aos países do seu entorno.

É de sinalar que esta dependência nom está causada pola orientaçom exportadora do sector agroalimentar galego. Ao contrário, as cifras monstram como entre 1998 e 2005 o incremento das importaçons foi acompanhado por um descenso das exportaçons. Nom existe umha dicotomia entre produzir para o consumo interno ou produzir para exportar, a questom é que papel tem a produçom doméstica e que papel tem os mercados internacionais, como fonte de aprovisionamento ou como destino da produçom interna (Maluf, R.S. 2000). No caso galego une-se a crescente dependência do exterior com a perda de peso nos mercados exteriores.

Tendo em conta os produtos aos que se deve a maior parte do déficit podemos concluir que a forte dependência exterior tem dous elementos explicativos fundamentais: as características do processo de modernizaçom da agricultura galega e a inexistência dumha indústria transformadora sólida. Comecemos polo primeiro destes dous elementos explicativos:

- O processo de modernizaçom da agricultura galega foi acompanhado dumha forte reduçom nalgumhas das principais produçons vegetais, fundamentalmente cereais $\mathrm{e}$ patacas, mas também parte das hortaliças.

- O processo de especializaçom gadeira, com um forte crescimento das produçons bovinas, mas também da carne de ave em comparaçom com mediados dos oitenta, apoiouse em boa medida na utilizaçom de alimentos comprados para animais em cuja fabricaçom as matérias-primas importadas som fundamentais (gráficas 2 e 3 ).
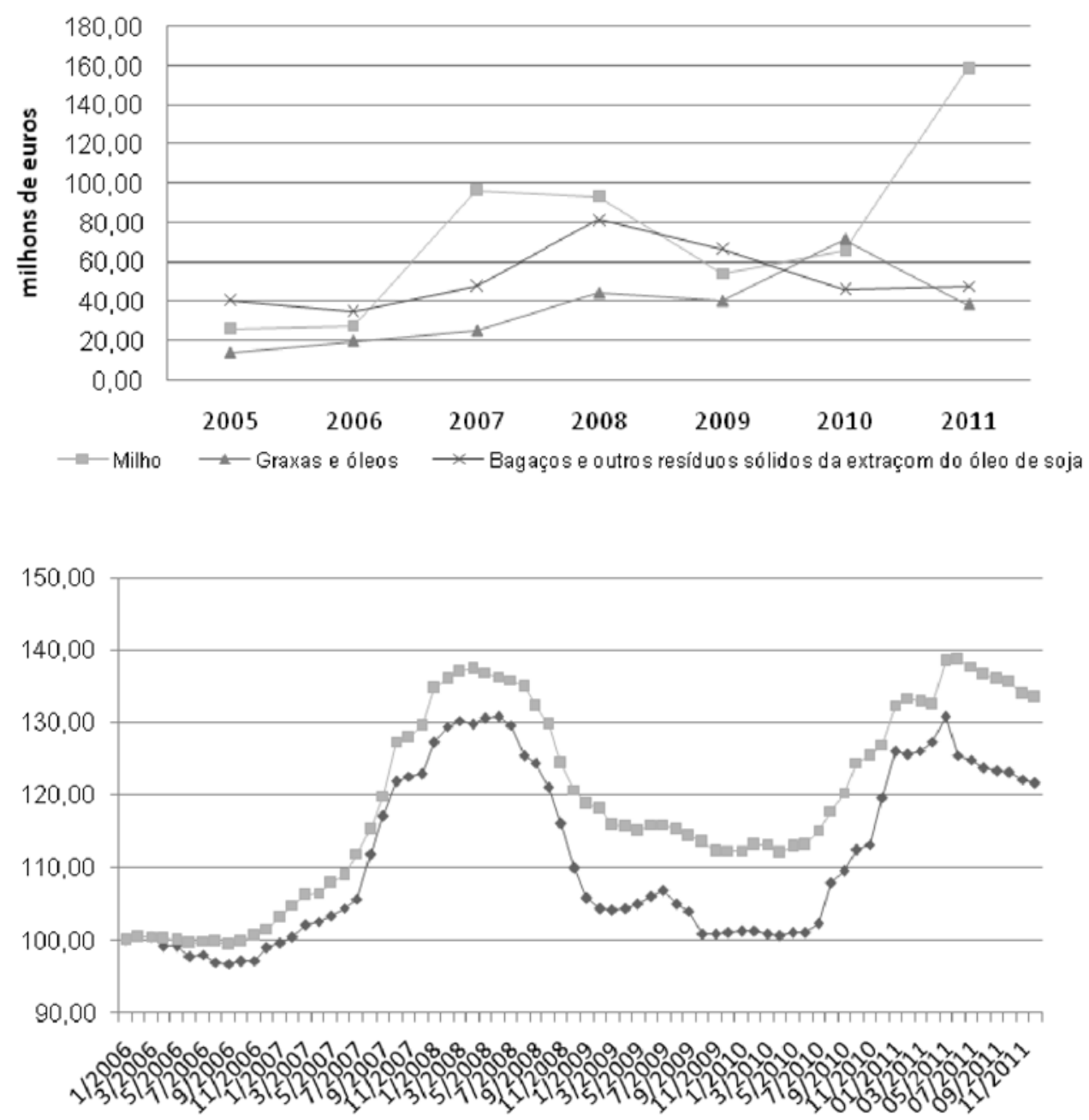

Gráfico 2.-Importaçons galegas de fora do EE de milho, graxas e óleos e bagaços e outros resíduos sólidos da extracçom do óleo de soja. Fonte: elaboraçomprópia a partir dos dados de DataComex
Gráfico 3.- Evoluçom dos preços dos concentrados para vacum de carne e vacum de leite no EE. Índizes base Janeiro $2006=100$. Fonte: elaboraçomprópia a partir do MAAMA 
Este fenómeno produz-se ao tempo que a SAU segue representando umha escassa percentagem da superfície total galega. Segundo a Conselharia do Meio Rural a superfície cultivada e a superfície a prados e pasteiros nom alcança um terço da superfície total, enquanto a superfície florestal representa dous terços, em boa parte com um escasso ou nulo aproveitamento produtivo. Este escasso peso da SAU no nosso território nom se explica já polo aproveitamento do mato, tal e como acontecia no passado. Tampouco se explica polas características do dos solos nem por razons climatológicas que impidam 0 desenvolvimento dumha actividade agrária. As razons temos de buscá-las no bloqueio no mercado da terra, na falta de ordenaçom territorial e na carência de políticas públicas destinadas a favorecer o aproveitamento produtivo das terras (López, E., 1996 ). Ao contrário durante muito tempo a política de florestaçom de terras agrárias foi um elemento central da política da Xunta da Galizaiv (Garcia Arias, A.I.; Pérez Fra, M., 2001).

Para explicar o déficit da balança exterior nom chega com fazer referência às características do processo de modernizaçom da agricultura galega, devemos acrescentarIhe que Galiza ocupa umha posiçom periférica na divisom internacional do trabalho agroalimentar. A debilidade da indústria alimentar radicada na Galiza é clara:

- É bem conhecida a marcada especializaçom gadeira do sector agrário galego: segundo a Conselharia do Meio Rural $67 \%$ do valor da produçom agrária procedia das produçons gadeiras em 2008v, pois bem umha parte importante destas produçons som exportadas sem transformar, rompendo a cadeia produtiva e criando valor e emprego noutras zonas.

- Por outra parte, a indústria agroalimentar galega está especializada em produtos de baixo valor acrescentado, produtos que geram um menor valor acrescentado por cada unidade de matéria-prima agrária transformada e que ademais, em termos gerais som produtos com umha procura menos dinâmica.

Neste sentido é significativo que a indústria láctea radicada na Galiza apenas represente $13 \%$ das vendas da indústria láctea do Estado Espanhol quando as entregas à indústria das exploraçons de bovino de leite galegas representam quase $40 \%$ das entregas totais de leite de vacum no EE.

O escasso desenvolvimento da agroindústria radicada na Galiza acentua a nossa dependência alimentar tendo em conta os câmbios nos padrons do consumo, em concreto a constataçom de que o crescimento econômico levou consigo um menor crescimento da procura de produtos agrários em comparaçom com a procura de alimentos (Efeito Malassis). Fenómeno associado à crescente concentraçom das vendas de alimentos nas grandes empresas transnacionais, tanto da transformaçom como da distribuiçom, mas também aos câmbios nas sociedades e nos hábitos de vida (Rastoin, J-L. e Ghersi, G., 2010).
Por último, dentro deste esquema nom se pode esquecer o processo de integraçom na CE/UE, a aplicaçom da PAC e das sucessivas reformas e a própria liberalizaçom dos fluxos agroalimentares do espaço comunitário com o exterior. Galiza entrou na CE/UE num momento no que a PAC passava de oferecer umha elevada garantia de preços e mercados a ser umha política na que essa garantia se reduzia, os mecanismos de control da produçom se geralizavam e posteriormente se implantava um sistema de ajudas directas ao rendimento claramente prejudicial em termos relativos para a agricultura galega.

\section{As debilidades do modelo de produçom gadeiro}

Em 2008 a produçom animal representava duas terças partes do valor da produçom da rama agrária a preços do produtor. As produçons de vacum aportavam perto arredor do $70 \%$ do valor da produçom animal, $46 \%$ o leite e perto de $24 \%$ a carne e o gado.

Entre os anos oitenta e finais da primeira década deste século as produçons de vacum experimentárom um forte crescimento em termos físicos e também a produçom de carne de ave e em menor medida de suíno. Um crescimento que se apoiou em boa medida no crescente peso dos alimentos comprados na alimentaçom animal. A MIOGA2005 pom de manifesto que a rama de fabricaçom de raçons para animais importou produtos agrícolas por valor de 133 milhons de euros, quase dous terços dos produtos agrícolas que utilizava como matéria-prima. Ademais as importaçons de graxas e azeite somavam perto de 24 milhons de euros mais. Mais de $80 \%$ da produçom de alimentos para animais se destinava ao mercado interno. Segundo dados da Conselharia do Meio Rural e do Mar referidos ao primeiro trimestre de 2011 o principal destino das raçons é o vacum com o $40 \%$ do total.

Esta dependência da produçom gadeira galega da importaçons de matérias-primas para a fabricaçom de alimentos evidenciou os seus perigos nas recentes altas nas quotizaçons internacionais. A suba dos preços fixo que se disparasse a factura destas importaçons para a economia galega. $\mathrm{O}$ valor das importaçons de milho de fora do EE multiplicárom-se por mais de três de 2006 a 2007, mantendo-se praticamente no mesmo nível em 2008; em 2011, acompanhando a suba das quotizaçons internacionais, alcançárom um valor que multiplica por quase seis o de 2006. A soma das três partidas que representamos na gráfica 2 passou de 83 milhons de euros em 2006 a 220 milhons em 2008, caiu ligeiramente depois para volver a subir alcançando 245 milhons em 2011. Embora umha parte destes insumo poda ir destinado a outros usos, a produçom de biocombustíveis entre eles, e nom aos alimentos para animais.

Este incremento das quotizaçons internacionais também se trasladou ao nível das exploraçons. Na gráfica 3

vi: Só a partir de 2005 se iniciou um breve período que puxo fim à política de subsidiar a florestaçom de terras agrárias, ao tempo que se introduzírom critérios de ordenaçom na utilizaçom das terras e evitar o abandono. Neste senso cumpre destacar instrumentos como o Banco de Terras ou o Contrato de Exploraçom Substentável que tinha entre os seus objetivos precisamente impulsionar sistemas de produçom gadeiros, também no leite, mais substentáveis em termos ambientais mas também económicos, é dizer, menos dependentes da compra de insumos externos e que se apoiassem mais nos recursos produzidos na própria exploraçom. Umhas políticas paralisadas ou abandonadas a partir de 2009.

v: Este ano é o último para o que a Conselharia do Meio Rural publicou as contas económicas da agricultura galega. 
observamos o forte encarecimento do preço do concentrado para vacum de leite e carne, coincidente com as altas nas quotizaçons internacionais. No caso concreto das exploraçons lácteas, o núcleo central da agricultura profissional galega, a compra de alimentos é a principal partida dos custos das exploraçons. Nom esqueçamos que umha elevada percentagem das que se mantenhem em activo aumentárom a sua produçom e a intensificárom, com um forte incremento da produtividade dos animais (produçom/vaca) e do consumo de alimentos concentrados, devido em parte às limitaçons na superfície (FernándezLorenzo, B. et al., 2009).

Segundo os dados do programa de gestom de exploraçons de leite da Conselharia do Meio Rural em 2009, último ano do que se publicárom os dados, a compra de alimentos para - gado representava $38 \%$ dos custos totais das exploraçons, sem contabilizar os custos de oportunidade (Barbeyto, F. e López, C., 2012). Agora bem naquela altura o preço do concentrado era notavelmente inferior ao que tiveron que enfrontar as explotacións posteriormente (gráfica 3). A imagem que mostram as exploraçons integradas na rede European Dairy Farmers é sem dúvida preocupante (Barbeyto, F. e López, C., 2012). A comparaçom entre as 11 exploraçons galegas desta rede em 2009 e as 280 do conjunto da UE evidenciam que os custos da compra de alimentos som superiores na Galiza 3'4 cêntimos/kg de litro-. Estes dados mostram umhas exploraçons com umha maior carga gadeira, mais dependentes da compra de concentrados $(6,9 \mathrm{~kg}$ concentrado/vaca e dia na Galiza frente a 6'3 na média da UE) e que fam um uso menos eficiente desse concentrado (3'1 kg de leite produzido por cada kg de concentrado consumido na Galiza frente a 4,1 na UE). Isto torna ao principal sector da agricultura galega (que nas últimas décadas manteve um maior dinamismo e ocupa umha parte muito importante da SAU) altamente sensível às variaçons da relaçom entre o preço de venda do leite e o preço de compra do concentrado. Nun cenário marcado pola eliminaçom do sistema de quotas, pola maior vinculaçom do mercado comunitário aos mercados internacionais das commodities lácteas e polo deterioro da relaçom entre o preço de venda do leite e o preço dos principias inputs da produçom láctea, o reforço da viabilidade das exploraçons lácteas exige um esforço no controlo dos custos de produçom.

\section{Conclusións}

Galiza mostra umha preocupante dependência alimentar do exterior tanto para o abastecimento da sua populaçom como para a alimentaçom da sua cabana gadeira. Questom que ademais de lastrar os resultados da balança comercial está pondo em risco a viabilidade dum importante sector da economia: a produçom gadeira.

Por outra parte, os dados expostos ponhem de manifesto que esta nom é umha situaçom conjuntural senom que desde finais dos anos 90 o saldo da balança exterior agroalimentar é cada vez mais negativo. Se bem esta pode ser umha tendência que obedece a dinâmicas comuns a outras economias vizinhas como podem ser a evoluçom dos modos de consumo (maior demanda de produtos alimentares industrializados) ou a concentraçom da distribuiçom de alimentos, em Galiza a situaçom agrava-se por fatores próprios.

Os fatores próprios que explicam esta dependência têm que ver por umha parte, com o escasso desenvolvimento da indústria agroalimentar, explicado pola posiçom periférica da Galiza na divisom internacional do trabalho da agroindústria. $\mathrm{E}$ por outra com as características e resultados do processo de modernizaçom da agricultura galega. O ajuste agrário implicou umha forte reduçom de produçons vegetais tradicionais e umha marcada especializaçom gadeira com umha crescente integraçom mercantil das exploraçons que modificárom completamente a tecnologia produtiva empregada. Mas ao tempo que o sector agrário mudava drasticamente o processo produtivo, persistiu um déficit na base territorial das exploraçons que impossibilitou para boa parte das mesmas a escolha de modelos menos intensivos e dependentes.

O bloqueio no mercado de terras, a falta de ordenaçom territorial, ou a carência de políticas publicas destinadas a favorecer o aproveitamento produtivo das terras, som responsáveis do escasso peso da SAU dentro da superfície total galega. Usos florestais nom ordenados e abandono estám lastrando os resultados do sector agrário e ao mesmo gerando problemas ambientais cuja manifestaçom mais visível som os incêndios.

Agradecementos Queremos expresar o nosso agradecemento ás suxestións feitas pólos revisores que contribuíron á mellora do presente artigo.

\section{Bibliografia}

Barbeyto, F y López, C. (2012). Resultados técnicoeconómicos das explotacións de vacún de leite en Galicia en 2009. Xunta de Galicia

CMR (s.d.) (2006). Anuario de Estatística Agraria 2005, D.G. de Investigación, Tecnoloxía e Formación Agroforestal. Consellería do Medio Rural.

Golay, C. (2009). Direito à alimentação e acesso à justiça. Exemplos em nível nacional e internacional. FAO, Roma.

FAO (2011). El estado de la inseguridad alimentaria en el mundo 2011. FAO, Roma.

García Arias, A.I.; Pérez-Fra, M. (2001). Análise e evolución da aplicación en Galicia do programa de axudas á forestación de terras agrarias. Em Revista Galega de Economía, vol. 10,1: 151-176.

Goodman, D., Sorj, B. e Wilkinson, J. (1987). From Farming to Biotechnology: A Theory of Agro-Industrial Development. Basil Blackwell, New York.

Fernández-Lorenzo, B.; Dagnac, T.; González-Arráez, A., Valladares, J.; Pereira Crespo, S. y Flores, G. (2009). Sistema de producción de leche en Galicia Evolución y estado actual. Em Pastos: Revista de la Sociedad Española para el Estudio de los Pastos, Vol. 39-2: 251-294. 
Graziano da Silva, J. e Tavares, L. (2008). Segurança alimentar e a alta dos preços dos alimentos: oportunidades e desafios. Em Segurança Alimentar e Nutricional, 15,1:6275 .

Leontief, W. (1986). Input-Output Economics. Oxford University Press. 2ond edition.

López Iglesias, E. (1996). Movilidad de la tierra y dinámica de las estructuras agrarias en Galicia. Análisis de los obstáculos que han frenado durante las últimas décadas las transformaciones en la estructura dimensional de las explotaciones. Ministerio de Agricultura, Pesca y Alimentación. Secretaría General Técnica, Madrid.

LLano Verduras, C (2004). Economía Sectorial Y Espacial: El Comercio Interregional En El Marco Input-Output. Tesis Doctoral. Instituto de Estúdios Fiscales.
Maluf, R.S. (2000). O novo contexto internacional do abastecimento e da segurança alimentar. Em Belik, W. e Maluf, R.S. (org.), Abastecimento e segurança alimentar, Unicamp-CPDA.

Rastoin, J-L. e Ghersi, G. (2010). Le système alimentaire mondial : concepts et méthodes, analyses et dynamiques. Quae, Paris.

Valdês, B. e López, E. (2008). Análise do complexo de produción agroalimentario galego a través das táboas inputoutput. CIEF-Fundación Caixa Galicia. 